\title{
A IMPORTÂNCIA DA PERCEPÇÃO DO ALUNO ADOLESCENTE NA REFLEXÃO DA PRÁTICA DOCENTE
}

\author{
Maura Lúcia Azevedo Salem ${ }^{1}$ \\ Lucia Helena Tiosso Moretti ${ }^{2}$ \\ ${ }^{1}$ Mestre em Educação pela UNOESTE. ${ }^{2}$ Doutora em Psicologia Clínica. Docente do Programa de Mestrado em Educação da UNOESTE
}

\begin{abstract}
RESUMO
Falar sobre adolescência, visão de si e do outro e ação docente é revelar o mérito desses fatores no ensino e na aprendizagem.O estudo analisou a visão que o aluno adolescente tem de si,de seus pares e do professor. $O$ estudo foi norteado pela pesquisa de campo descritiva. Participaram 22 professoras com idade de 28 a 54 anos, 40 alunos, de $5^{\mathrm{a}}$ à $8^{\mathrm{a}}$ série do Ensino Fundamental e 15 alunos de $2^{\mathrm{a}}$ à $4^{\mathrm{a}}$ Etapa EJA, de 10 a 21 anos de idade. A pesquisa foi realizada num Colégio Estadual do Noroeste do Paraná. Foram aplicados questionários aos docentes e alunos, visando uma análise sobre a percepção destes sobre si mesmos, do professor e da adolescência. O estudo mostrou que os docentes não tiveram base adequada para atuar com o aluno adolescente e percebem o aluno desinteressado e indisciplinado.O diálogo,afeto e experiência ajudam sua prática pedagógica;o desinteresse e indisciplina, dificultam. Os jovens vêem a si mesmos como responsáveis,mas o outro como indisciplinado. Para eles, os professores os vêem como desmotivados e desinteressados. A incompatibilidade entre as percepções do professor e do jovem indica a necessidade de um trabalho de conscientização com os alunos e uma ação voltada à formação docente.
\end{abstract}

Palavras - chave: prática pedagógica - adolescência - percepção de si mesmo - ensino e aprendizagem - desinteresse - indisciplina

\section{THE IMPORTANCE OF ADOLESCENT STUDENT'S PERCEPTION IN THE REFLEXION OF THE TEACHER'S PRACTICE}

\begin{abstract}
To talk about adolescence, self-perception, the other perception, and teacher's practice is to expose the aptitude of these factors in teaching and learning. The study analysed the self-perception of the adolescent student about yourself, of theirs equals and of theirs teachers. The used methodology was the field research. The sample was composed for 22 teachers and 40 students of 5th to 8th series of the Elementary School and 15 students of $2^{\text {nd }}$ to 4 th stage in EJA - Adult Young Education $\left(6^{\text {th }}\right.$ to 8 th Supplementary series of Elementary School), situated in a age group of 10 the 21 years old. The research was carried out in a northwestern State College of Paraná State. A questionnaire was applied to the teachers and the students to get information about their own perception, of the teacher and about the adolescence. This study pointed out that teachers did not have a basis to work with the adolescent student in their academic education and noted the student not interested and not disciplined. The dialogue, the friendship and the practice to favour their pedagogical activity while the no interest and no discipline difficultate. The young has positive ideas as nice and responsible about their own perception, but have negative ideas above adolescent like rebel and irresponsible. For them, the teachers see them like no motivated and disinterested. This lack of compatibility between the perceptions of the teacher and of the adolescent student indicates the necessity of awareness with the students and a project the teachers formation.
\end{abstract}

Key words: Pedagogical practice, adolescence, perception of oneself, teaching and learning, disinterest, indiscipline. 


\section{INTRODUÇÃO}

A adolescência é um período de transição no tempo da vida humana, ligando a infância e a vida adulta.Entender o significado da adolescência é importante porque os jovens de hoje são o futuro de qualquer sociedade.

Desde a Grécia antiga, Platão e Aristóteles comentavam a natureza da juventude e Platão (século IV a.C), dizia que o raciocínio era uma característica dos jovens e que deveriam estudar ciência e matemática.Aristóteles, porém, argumentava que o aspecto mais importante da adolescência era a capacidade para selecionar e esse requisito signifcava maturidade.

Aristóteles também percebeu uma conduta egocêntrica nos jovens. No século XVIII Rousseau apontou que criança e adolescente não é igual a ser um adulto. A exemplo de Platão, Rousseau admitia que o raciocínio desenvolve-se na adolescência. .(SANTROCK, 2003, p.3)

A adolescência é uma fase da vida onde o jovem sofre mudanças que repercurtem em sua vida pessoal e escolar, principalmente. Durante o período de transição, o adolescente oscila em comportar-se ora como criança, ora como adulto. (BERGER, 2003)

Segundo Outerial (2003), a adolescência é considerada um fenômeno psicológico que gera diferentes facetas conforme o meio social, econômico e cultural no qual o jovem se desenvolve. É constituída por fases,com início e fim não muito precisos: a inicial (10 a 14 anos), a média (14 a 17 anos) e a final (17 a 20 anos).

A palavra "adolescência" tem dupla origem etimológica e caracteriza muito bem as peculiaridades desta etapa da vida. Ela vem do latim ad (a, para) e olescer (crescer), significando a condição ou processo de crescimento, em resumo, o indivíduo apto a crescer. (OUTEIRAL, 2003).

De acordo com Sartrock (2003, p. 19), os fatores de importância na adolescência estão relacionados aos processos biológicos, cujo interesse está no papel da hereditariedade e meio ambiente, da evolução e da saúde no desenvolvimento do jovem; aos processos cognitivos, aos contextos em que ocorrem o desenvolvimento do adolescente, ao desenvolvimento social e da personalidade, incluindo o "eu" e a identidade, o gênero, a sexualidade, o desenvolvimento moral e a realização, entre outros.

A diversidade de teorias acerca da adolescência faz com que a compreensão do desenvolvimento do adolescente seja um projeto mais desafiador, porém todas elas têm contribuído sobremaneira nessa fase do desenvolvimento humano.(Ibid., p.25)

Um aspecto relevante do perfil do adolescente está relacionado à percepção de si mesmo, de sua auto-estima - dimensão autoavaliadora global do eu, outrossim denominada de auto - imagem. A autocompreensão é a evidência cognitiva do eu, a substância e o conteúdo de autoconcepção do adolescente. Essa autocompreensão possibilita as bases racionais de identidade do jovem.

A aparência física percebida é fator que contribui para a uma autoestima positiva;em seguida, a aceitção dos pares, sobretudo associada a atitudes parentais como afeto e concessão de liberdade dentro de limites determinados.

\section{A FORMAÇÃO DO PROFESSOR}

A formação do professor constitui o ato de formar o docente para o exercício profissional. Para Veiga (2006), o termo "formação" é, "o ato ou modo de formar" que compreende "dar forma a algo, ter a forma; pôr em ordem; fabricar; tomar forma; educar". 
A formação de professores envolve a tarefa de capacitar o profissional para educar, aprender, ensinar, avaliar, pesquisar, exercer a profissão da "docência" que no sentido etimológico da palavra vem do latim "docere" que significa ensinar, instruir, mostrar, indicar, dar a entender.

Segundo Freire (1999), alguns conteúdos são obrigatórios para a formação docente, tornando-se saberes indispensáveis. Um deles é de que o professor,a partir de sua experiência formadora assuma-se também como sujeito da produção do saber, com a convicção de que ensinar não é transferir conhecimento, mas criar condições para que aconteça a sua produção ou construção.

O processo de formação de professores, de acordo com Veiga (2006), deve ser compreendido dentro de um contexto social, histórico, político e econômico, comprometido com a inclusão social através de perspectivas emergentes e emancipatórias.

Perrenoud (2002), explica que a prática reflexiva constitui-se em uma forma de aprendizagem e regulação que ao ser realizada através de um exercício metódico, pode tornar-se autoformação e inovação abrindo espaço para a construção de novas práticas e competências, não ficando só no saber - analisar, mas que leve a tomar consciência do que se faz.

Libâneo (2002, p.86), fala da necessidade do professor em desenvolver uma capacidade reflexiva de sua própria prática, o que levaria a pensar, refletir sobre o seu trabalho:Segundo ele, - professorado apresenta deficiências significativas em relação ao aprender a pensar, de forma a necessitar adquirir estratégias de refletir e pensar sobre o próprio pensar.

Nóvoa (2002), ao referir-se às competências exigidas para a prática do professor, comenta sobre duas delas: a de organização e a compreensão do conhecimento.
O professor, além de ser um transmissor de conhecimento, é uma pessoa que trabalha no interior de uma sala de aula, é, acima de tudo, um estruturador de aprendizagens.

A partir desses referenciais os objetivos da pesquisa centraram-se em:

Analisar a visão que o professor tem de seu aluno adolescente e quanto esta percepção influencia a sua prática pedagógica,

$\rightarrow$ Identificar a percepção do aluno adolescente em relação a si mesmo, da adolescência em geral, de seus professores;

$\rightarrow$ Apontar as expectativas do aluno adolescente em relação a seus professores e à escola, como também os pontos positivos e negativos em relação ao processo ensino - aprendizagem;

$\rightarrow$ Verificar as possíveis diferenças entre a percepção do aluno, de si e do outro, nos períodos matutino, vespertino e noturno.

Quanto à proposição metodológica, o trabalho foi desenvolvido segundo uma metodologia de pesquisa de campo, descritiva, em seus aspectos quantitativos e qualitativos.

O estudo foi realizado com:

1) 22 professores, todos do sexo feminino, situados na faixa etária de 28 a 54 anos, atuando no magistério de 2 a 33 anos;

2) 217 alunos do sexo feminino e masculino, distribuídos entre 8 turmas de $5^{\mathrm{a}}$ à $8^{\mathrm{a}}$ série, de 10 a 15 anos de idade.Foram sorteados aleatoriamente cinco alunos por turma para a análise das respostas dos questionários, perfazendo um total de 40 alunos;

3) 56 alunos de $6^{a}$ à $8^{a}$ série de EJA (Educação de Jovens e Adultos), do sexo feminino e masculino, com idade de 15 a 21 anos, dos quais foram sorteados cinco alunos por turma para a análise das respostas dos questionários aplicados, num total de 15 alunos.

A pesquisa foi realizada no Colégio Estadual Costa Monteiro - Ensino Fundamental Regular e EJA - Ensino Médio - situado na cidade 
de Nova Esperança, Paraná, no período de agosto a outubro do ano de 2005 , obedecendo às seguintes fases: .

1) Reunião com a Direção e equipe de pedagogos do Colégio, explanando sobre a importância do projeto, bem como a exposição do mesmo e solicitando autorização para o seu desenvolvimento;

2) Solicitação de autorização dos pais dos alunos e assinatura do Termo de Livre Consentimento para aplicação do questionário.

3) Elaboração e aplicação de um questionário aos professores $^{1}$, contendo informações gerais e 6 questões abertas;

4) Elaboração e aplicação de um questionário aos alunos incluindo dados gerais e 7 questões abertas;

5) Análise dos dados quantitativa e qualitativamente segundo os teóricos que nortearam a presente pesquisa;

6) Encontro com os professores,pais e alunos para apresentar os resultados da pesquisa.

\section{RESULTADOS E DISCUSSÃO}

\section{I - Em relação aos dados coletados dos professores:-}

Todos os professores eram do sexo feminino, de 28 a 54 anos de idade e 100\% cursaram Especialização na área de formação. Atuam de $5^{\mathrm{a}}$ à $8^{\mathrm{a}}$ série do Ensino Fundamental Regular e EJA (Educação de Jovens e Adultos). As disciplinas ministradas por eles são: Ciências; Educação Artística; Educação Física; Geografia; História; Inglês; Língua Portuguesa e Matemática.

Em sua formação acadêmica, 15 professores $(68,18 \%)$, não tiveram embasamento para sua atuação com o aluno adolescente, 4

\footnotetext{
1 Assinatura do Termo de Consentimento pelos professores
}

professores tiveram subsídios (18,18\%), 3 professores disseram que receberam um pouco de informação (13,68\%).

Libâneo (2002, p. 91), coloca que os cursos de formação inicial e cursos de formação de magistério estão ofertando uma prática deficitária, formando mal os futuros professores.

As universidades formam mal os futuros professores, [...]. Poucas universidades brasileiras têm uma política definida em relação à formação de professores para o ensino fundamental e médio [...]. Com isso, os professores saem despreparados para o exercício da profissão, com um nível de cultura geral e de informação extremamente baixo, [...].

Os fatores facilitadores da prática pedagógica com o aluno adolescente foram: o diálogo, relação professor/aluno, o afeto, experiência, respeito, atividades que os alunos gostam, conhecimento, incentivo, sensibilidade, bom senso, acordo comum, traçar metas, paciência, flexibilidade.

Entre os que aspectos dificultam estão: falta de compromisso, de interesse, de limites, de respeito, de entendimento, de sintonia, de autoestima (é muito baixa entre os alunos), rebeldia, agressividade, desatenção, preguiça, liderança negativa, não querem aprender, indiferença, falta de material pedagógico,etc.

Quanto ao papel do professor na formação pessoal do aluno adolescente, os docentes apontaram: dar apoio, ensinar conteúdos, ser modelo, exercitar a capacidade, ser confiável, ser mediador, ser educador, passar conhecimento, posicionar-se diante dos fatos da realidade, demonstrar equilíbrio, passar valores, respeitá-los, ajudá-los nas dificuldades, preparálos para reflexões críticas; ser amigo, orientar, motivar, desenvolver a sensibilidade, criatividade, fazê-lo compreender seu papel na sociedade, a lidar com perdas e frustrações, a encontrar o verdadeiro sentido da vida, ser um cidadão. 
Podemos observar que o papel do professor na formação pessoal do aluno é de grande responsabilidade e exige não só competência teórica e prática como também "ser pessoa" e neste sentido afirmamos que não se passa aquilo que não têm.

Perrenoud (2002), descreve que alunos do mundo inteiro quando pesquisados sobre o que esperam de seus professores, respondem, que esperam um certo calor e senso de justiça.

Em relação à percepção do professor sobre seu aluno adolescente, $68,2 \%$ responderam que os jovens mostram estar perdidos, desinteressados, descompromissados, sem limites, indisciplinados; $13,6 \%$ explicaram que os jovens os procuram para orientação e $9,1 \%$, descreveram seu aluno como: crítico, sincero, afetivo. Isto nos mostra que a maioria dos professores vem tendo dificuldade em atuar junto a estes alunos, visto a falta de limites desses adolescentes .

Quanto a este aspecto, Outeiral (2003),

coloca que:

Limite é uma palavra que tem muitas vezes, uma conotação negativa, ligada erroneamente à "repressão", "proibição", "interdição", etc... No entanto, limite é algo muito além disso (e um tempo) protegido, dentro do qual o adolescente poderá exercer sua espontaneidade e criatividade sem receio e riscos, tanto para si como para os outros. (OUTEIRAL , 2003, p. 30),

As crianças e os adolescentes pedem limites e estes os ajudam a organizar sua mente. Ninguém nasce com limites e que colocar limites significa se envolver com o adolescente, buscando contê-lo, suportando suas reclamações e protestos, enfim, enfrentar dificuldades.

\section{II - Dos questionários aplicados aos} alunos

A - Dos alunos que cursam de $5^{\mathrm{a}}$ à $8^{\mathrm{a}}$

\section{Série do Ensino Fundamental (Turmas}

Matutina e Vespertina).

Em relação aos dados gerais dos alunos, o gráfico a seguir,demonstra a faixa etária e séries cursadas.

O Gráfico 1 abaixo demonstra a faixa etária dos alunos de $5^{\mathrm{a}}$ à $8^{\mathrm{a}}$ série do Ensino Fundamental.

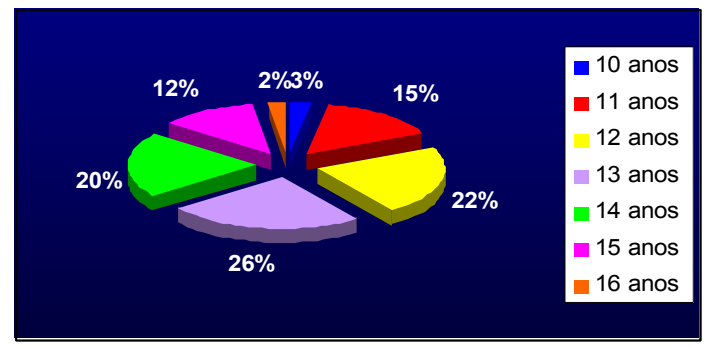

Gráfico 1. Faixa etária dos escolares

Quanto à análise das respostas dos questionários aplicados aos alunos de $5^{\mathrm{a}}$ à $8^{\mathrm{a}}$ do Ensino Fundamental, a questão como é o adolescente hoje, mostrou: condutas de rebeldia, irresponsabilidade, falta de respeito pela maioria dos alunos; alguns denotam características de quase adulto ao adolescente Para os alunos,a percepção que eles têm de si mesmos, revelou que a maioria atribuiu respostas positivas em relação a si como, por exemplo: "Eu me acho": alegre, estudioso (a), tranqüilo, responsável, bonito, calmo. Isto demonstra uma auto-estima positiva, que pode contribuir para um bom desempenho escolar.Apenas um dos alunos disse sentir-se perseguido.

De acordo com a maioria dos alunos, os professores vêem o adolescente hoje como: rebelde, bagunceiro, mal educado; só um aluno acredita que o professor os vê com carinho e respeito, outros dois acreditam que depende do 
adolescente e um entende que é visto como adulto.

$\mathrm{Na}$ questão $\mathrm{O}$ que você espera de seus professores?, elencamos: "que os professores ensinem mais", "sejam bons", "legais", "demonstrem carinho", "dêem atenção", "transmitam alegria", que "não reclamem do aluno" e "o veja como pessoa normal". Percebemos que algumas respostas são compatíveis com as colocações que os professores fizeram quando indagados sobre 0 que pensam que os alunos esperam deles.

Quanto às expectativas que os alunos têm da escola, muitos disseram que esperam uma escola boa, que não haja brigas ,que proporcione educação e que ela "garanta" um bom emprego e um futuro promissor.

No que diz respeito à opinião dos alunos em relação aos seus professores, a maioria dos alunos considerou seus professores legais, bons; mas, também há aqueles que passam medo, são chatos, gritam.

Os pontos positivos indicados em relação às aulas ministradas pelos professores foram: que ensinam bem, dão alegria, as aulas são proveitosas, fazer exercício fora da sala, professores amigos, quando os tratam igualmente,ajudam a amadurecer,as matérias lecionadas, as aulas de educação física.

Entre os pontos negativos, destacaram: quando não entendem nada, levam "broncas", alunos que perdem o controle, perseguição, bagunças, brigas, empurrões, quando a professora senta e finge dar aula, aulas que são um tédio, algumas aulas chatas, professora que não explica, professores que não estão nem aí para o aprendizado deles.

Estas respostas evidenciam que os alunos valorizam aulas diferentes, diversificadas, o aprendizado durante as aulas com envolvimento de ambos, aluno e professor, bem como os professores que os respeitam e dão
atenção.Todavia, alertam para aqueles docentes que respeitam seus alunos,mas não se preocupam com o ensino e a educação dos mesmos.

\section{B - Dos questionários aplicados aos} alunos do EJA (Turmas do Noturno)

A análise dos dados dos alunos da $6^{\mathrm{a}}$ à $8^{\mathrm{a}}$ série - $2^{\mathrm{a}}$ etapa da EJA (Educação de Jovens e Adultos), quanto à faixa etária, encontra-se no Gráfico 2 abaixo.

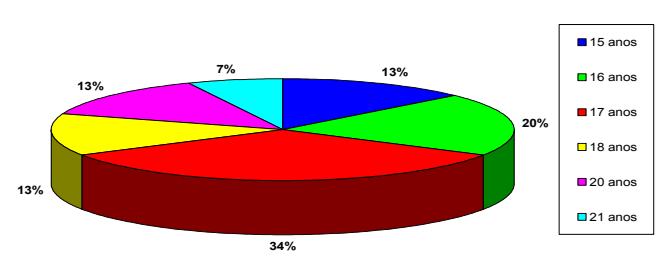

Gráfico 2. Idade dos alunos $6^{a}, 7^{a}$ e $8^{a}$ série do EJA

Em relação às respostas dos alunos de $6^{a}$ à $8^{\mathrm{a}}$ série ( $2^{\mathrm{a}}$ Etapa EJA) Noturno, o adolescente hoje é visto como: rebelde, irresponsabilidade, mal educado e imaturo, desobediente,agressivo, violento, leva os estudos na brincadeira, só quer saber de festas, experimentar sensações diferentes, moderno, inteligente, só pensa em "ficar", não tem responsabilidade com nada, quer ser dono de si. Para estes alunos, o adolescente hoje não tem responsabilidade para com a escola.

Erikson (1998,p.96), descreve que os estágios do desenvolvimento organizam e operacionalizam as aquisições realizadas, definidas como "crise psico-social". Aqui, o termo crise significa "uma fase crucial de crescente vulnerabilidade e potencial, logo, a fonte ontogenética da força e do desajustamento degenerativos". 
Quando questionados Como você se vê, se percebe?, a maioria apresentou conotações positivas em relação a si como: sou muito responsável e, uma pessoa legal, bonita, otimista, moderna, inteligente, gosto de estudar, tenho minhas responsabilidades, não gosto de brincar na escola, sou extrovertida.Dois jovens revelaram ser rebeldes e que não querer responsabilidades.

Ao responderem "como você acha que os professores vêem o adolescente hoje"?, os alunos relataram que o professor o vê como: mal educado, irresponsável, rebelde, leva as coisas na brincadeira, só pensa nele mesmo, só quer bagunçar, não pensa, muito bagunceiro, falta com respeito em sala de aula.

A idéia que 0 aluno tem sobre a percepção dos professores à respeito do jovem é de conotação negativa e grande parte equiparase à visão que eles alunos apresentam. Os alunos revelaram o adolescente hoje como quem: leva os estudos na brincadeira, só quer saber de festas, experimentar sensações diferentes, rebelde, moderno, inteligente, só pensa em ficar, irresponsável, quer ser dono de si.

Esses dados indicam compatibilidade entre a percepção do professor sobre a adolescência hoje e como os jovens descrevem seus pares nos dias atuais.

Os alunos esperam que seus professores expliquem o conteúdo das matérias e que sejam compreensivos, pacientes e legais.

Freire (1999,p.25) e Cavalcante (2004, p.47), mostram a importância de o aluno adolescente respeitar seu professor - "se o adolescente admira e respeita seu professor, ele já tem meio caminho andado para desenvolver os conteúdos curriculares". "Não há docência sem discência, ambas se complementam e se explicam".

Sobre o que os alunos esperam da escola, a maioria das respostas estava centrada em: que seja boa, melhore a educação, dê mais apoio aos alunos que trabalham, que tenha uma boa aula, um bom professor, um bom diretor, aula comunicativa, mais sossego por que tem muitas brigas, muitos eventos, melhoria nas aulas de educação física.

Os alunos esperam uma escola que proporcione e uma boa educação, segurança, etc. A escola constitui um espaço privilegiado das evidências educativas.

A opinião deles sobre seus professores revelou: serem legais, alguns são bons, outros são chatos, ótimos disciplinadores, educados, explicam bem.Percebemos aqui a sensibilidade dos alunos quanto à qualidade da relação com seus professores e sua importância no processo ensino - aprendizagem.

Apontando os pontos positivos relacionados às aulas ministradas pelos professores, foram obtidas as seguintes respostas: ensinam bem, professor legal,a matéria é interessante, gostamos quando passa filme, o jeito que trata os alunos, gosto de todas as aulas. Os negativos: o professor não explica direito, matéria ruim, professor que não sabe dar aula, quando fala muito alto com os alunos.

Pudemos observar que na medida em que o professor é em aceito pelo aluno,seja porque ele "sabe" ministrar uma aula, seja pelo fato de respeitá-lo, a educação escolar torna-se mais acessível e possibilita melhor aprendizagem do aluno.A formação docente deve prever tais fatores.

\section{CONCLUSÃO}

Embora a adolescência seja vista como uma época de tormenta e estresse, a pesquisa mostrou que muitos jovens têm um relacionamento de razoável para bom com seus colegas e professores, embora apontem divergência quanto ao conceito de ser adolescente hoje com a visão de si mesmos. 
A percepção que o adolescente têm de si, do adolescente em geral, de seus professores e da escola, bem como a percepção que o professor têm deste aluno e da adolescência em geral, pode contribuir para uma prática pedagógica salutar, considerando também a formação do professor para sua atuação junto a estes alunos adolescentes.

Nesse sentido, acatamos algumas das formulações feitas por Masetto (2004, p. 198), no que diz respeito ao processo ensino aprendizagem e que podem nos ajudar a entender e efetuar propostas junto ao Colégio. São elas:

1. É importante a substituição da metodologia tradicional, assentada em aulas expositivas, por técnicas que permitam atingir os vários objetivos educacionais, estimulando 0 aluno para aprender e possibilitem sua participação no processo de aprendizagem;

2. Os objetivos educacionais devem ser mais elucidados e abrangentes, implicando os aspectos cognitivos, aptidões e competências humanas e profissionais, atitudes e condutas requeridas pela sociedade atual, bem como comportamento ético e profissional,

3. O professor deve ser mediador pedagógico, promovendo um vínculo de coresponsabilidade com seus alunos, atuando em equipe;

4. É importante que os professores sejam preparados para modernização no ensino e assumam projetos inovadores mediante um trabalho de formação docente contínua; sobretudo possibilitarem trocas de experiências com os demais colegas Considerando que todas as professoras possuem curso de Licenciatura em pelo menos uma das disciplinas do Ensino Fundamental e que estas oportunizaram a atuação junto a alunos de $5^{\mathrm{a}}$ a $8^{\mathrm{a}}$ série e $2^{\mathrm{a}}$ grau, causou-nos estranheza que estes cursos não possibilitaram embasamento teórico para estes profissionais.

Quanto a esse aspecto, Libâneo (2002, p. 81) cita que:

Poucas universidades brasileiras têm uma política definida em relação à formação de professores para o ensino fundamental e médio. Há um desinteresse geral dos Institutos e Faculdades pelas licenciaturas. Com isso, os professores saem despreparados para o exercício da profissão, com um nível de cultura geral e de informação extremamente baixo $[\ldots]$

As pesquisas sobre formação e profissão docente apontam para uma revisão da compreensão da prática pedagógica do professor, que é visto como mobilizador de saberes profissionais. Considera-se, assim, que este, em sua trajetória, constrói e reconstrói seus conhecimentos conforme a necessidade de utilização dos mesmos, suas experiências, seus percursos formativos e profissionais Observamos compatibilidade entre a percepção do aluno e do professor em relação ao adolescente, apontando que a maioria dos professores, $68 \%$, percebe o adolescente como desinteressado, descompromissado, sem limite, indisciplinado, perdido.

Comparando os resultados obtidos com os alunos, a maioria deles apresentou uma auto imagem negativa, de rebeldia, irresponsabilidade. A visão do aluno e do professor neste aspecto é coincidente.

A percepção sobre o adolescente em geral por parte do aluno e do professor apresenta uma visão positiva? Tanto a visão do aluno quanto à do professor é bastante negativa em relação ao adolescente; portanto, compatíveis em suas descrições. O jovem mostra como ele realmente se comporta perante o professor $\mathrm{e}$ seus pares. 
Isto pode significar que o adolescente esteja representando os outros adolescentes, em parte, através de si mesmo, o que pode gerar sérios problemas de comportamento, no qual o adolescente não reconhece estar, por exemplo, se comportando mal.

De acordo com Outeiral (2003), freqüentemente os adolescentes se preocupam com expectativas que as demais pessoas têm em relação a ele e por isso alimentam um falso eu. (falso"self")

As conotações negativas atribuídas ao adolescente tanto por parte dos alunos, quanto dos professores mostra-nos um comportamento púbere, que leva à indisciplina na escola, repercutindo na visão do professor até como fatores relevantes em relação aos aspectos que dificultam sua prática junto a estes alunos Grünspun (2004, p.59), afirma que:

A disciplina é a técnica através da qual atingimos a autoridade e liberdade;é a técnica da obediência. A disciplina é o treino, a experiência que molda, corrige, reforça e aperfeiçoa a faculdade de obedecer às normas internas do indivíduo.

A disciplina, portanto, possibilita à pessoa, o desenvolvimento de uma conduta para viver em sociedade.As atitudes indisciplinares são dificuldades apresentadas pelos alunos que provocam dúvidas de difícil solução, tornando a relação com eles incerta, difícil e trazendo impasses nas decisões que precisam ser tomadas em sala de aula.

Para Grünspun (2004, p.61), dentre os fatores que podem promover este comportamento indisciplinar estão: padrões familiares divergentes; pais que esperam obediência implícita; restrições excessivas aos filhos; exigências que extrapolam os limites da compreensão; permissibilidade exagerada, entre outros.
A maioria dos alunos alega que suas expectativas estão em torno de que seus professores expliquem bem, que sejam legais e pacientes e da mesma forma apontam os pontos positivos das aulas - continuem dando boas aulas, sejam amigos, mantenham um bom relacionamento com eles, etc.. Os pontos negativos posicionam-se como os professores relacionamento com eles, etc.. Os pontos negativos posicionam-se como os professores não explicam direito, professor chato e aula chata.

Retomamos as colocações de Masetto (2004, p.199), quando ele se refere às mudanças necessárias no ensino (para todos os níveis). Abaixo estão algumas das proposições elencadas por ele que poderão ajudar professor - aluno e instituição escolar a melhorar sua forma de funcionar, bem como possibilitará o desenvolvimento da motivação por parte do aluno.

1. A escola pode re-organizar e flexibilizar o projeto pedagógico,

2. Identificar qual é o papel das disciplinas como componentes curriculares, arroladas segundo os fins formativos requeridos e como fonte de informações necessárias para o aluno que se pretende formar;

3. Possibilitar a integração das disciplinas e atividades curriculares em torno dos objetivos educacionais, superando o isolamento e a fragmentação do conhecimento;

É necessário rever a infra-estrutura de apoio escolar/institucional para projetos inovadores, incluindo biblioteca atualizada e informatizada, laboratórios adequados.

Nota-se que as expectativas dos alunos em relação aos professores e a escola convergem entre si. Deve-se ressaltar que a resposta às expectativas que criamos sobre 
alguém ou alguma coisa, muitas vezes reflete uma motivação positiva ou negativa de nossa parte. A escola deve considerar às expectativas do aluno adolescente, pois muitas vezes a preocupação da escola com o futuro dele retrata em menor importância com o momento atual vivido por esses adolescentes

O professor em momento algum pode esquecer ou relevar a sua importância na formação moral do aluno, pois para Freire (1999, p. 37) "Se se respeita a natureza do ser humano, o ensino dos conteúdos não pode dar alheio à formação moral do educando. Educar é substantivamente formar."

O professor não pode se esquecer que é humano e falho. Criar muitas expectativas em relação ao seu papel na formação do aluno pode levá-lo à frustrações e desânimo em torno da sua prática junto aos mesmos. Por isso é importante considerar o que é realmente significativo em sua formação e o quanto ele se dedica ao seu trabalho.

Nesta pesquisa observamos a visão positiva que a maioria dos alunos têm de seus professores. Este é um fator relevante, pois, sabe-se que isto pode levar a um bom relacionamento entre ambos, o que contribui para as práticas de ensino-aprendizagem.

Ao desenvolvermos esta pesquisa verificamos que a percepção do aluno em relação a si e ao outro é congruente entre os pesquisados dos períodos matutino, vespertino e noturno, apesar da diferença de idade e do meio em que vivem.

A visão que o professor tem de seu aluno e vice - versa indicou-nos algumas possilidades de trabalho para com ambos, envolvendo, é claro, a instituição escolar e sua equipe de trabalho.

Com os docentes, a realização de encontros mensais para tratar de temas relacionados à sua formação, reflexões sobre sua prática pedagógica, a partir de leituras e discussão do Projeto Pedagógico do Colégio, com os alunos, efetivar um calendário de reuniões mensais visando a discussão de temas selecionados por eles, para construir um trabalho de conscientização e auxiliá-los na construção de sua identidade, conforme as respostas elencadas pelos mesmos nos questinários.

Conhecer as percepções positivas e negativas em relação ao aluno, professor e à escola conduz-nos a reflexões da prática pedagógica docente o que contribuirá para uma melhoria da mesma.

A realização de encontros com pais abordando questões primordiais sobre a adolescência e sua relação com o processo ensino - aprendizagem e temas relacionados o interrelacionamento familiar permitirá melhor esclarecimento sobre a atuação da escola na vida familiar desses alunos.

É de suma importância que o professor esteja preparado para receber 0 adolescente, conhecendo todo o processo de modificações que ocorre durante seu desenvolvimento, levando-o a compreender melhor o seu aluno e a implementar sua prática junto aos mesmos

\section{REFERÊNCIAS BIBLIOGRÁFICAS}

BERGER, K. S.O. O desenvolvimento da pessoa: da infância à terceira idade.Rio de Janeiro: Livros Técnicos e Científicos, 2003.

CAVALCANTE, M. Adolescentes: Nova Escola, Edição 175, p. 46 - 49, setembro, 2004.

ERIKSON, E. H. O ciclo de vida completo.Porto alegre: ArtMed, 1998.

FREIRE, P. Pedagogia da autonomia: saberes necessários à prática educativa. São Paulo: Paz e Terra, 1999. 
GRÜNSPUN, H. Autoridade dos pais e educação da liberdade. Rio de Janeiro: Wak, 2004.

LIBÂNEO, J. C. Adeus professor, adeus professora? Novas exigências educacionais e profissão docente. São Paulo: Cortez, 2002.

MASETTO, M. Inovação na educação superior. Interface - Comunic., Saúde, Educ., v. 8, n.14, p.197-202, set.2003lfev.2004.

NÓVOA, A. Formação de professores e trabalho pedagógico. Lisboa:-Porto: 2002.

OUTEIRAL, J. O. Adolescer. São Paulo: Revinter, 2003.

PERRENOUD,P. A prática reflexiva no ofício do professor.Porto Alegre: ArtMed, 2002.

VEIGA, I. P. A. Docência: formação, identidade profissional e inovações didáticas. Anais do XIII ENDIPE. Recife, 2006 